\title{
Empreendedorismo e Jovens Empreendedores
}

\author{
Dario de Oliveira Lima-Filho ${ }^{1}$ \\ Renato Luiz Sproesser ${ }^{2}$ \\ Eber Luis Capistrano Martins ${ }^{3}$
}

\section{Resumo}

Este estudo tem como objetivo analisar as características de um grupo de jovens empreendedores e suas opiniões quanto à importância da família, educação formal e formação complementar em sua trajetória para o empreendedorismo. Foi conduzida uma pesquisa, usando entrevistas em profundidade, junto a uma amostra de 16 jovens empreendedores da classe média, egressos de cursos de empreendedorismo. Os resultados apontam que, na trajetória para o empreendedorismo, a herança da cultura familiar, motivando interesses de reprodução e ascensão social, foi decisiva para que esses jovens se encaminhassem para o mundo dos negócios. O sucesso desses jovens empreendedores veio com a dedicação ao trabalho, sendo que os desafios $e$ incertezas foram enfrentados com o apoio e valores recebidos da família. O discurso do jovem empreendedor é otimista e o coloca como indivíduo cuja história de vida valoriza a independência no modo de agir e a necessidade de garantir seu futuro, conduzindo seu próprio caminho.

Palavras-chave: Novos negócios. Formação empreendedora. Educação empreendedora.

\section{Introdução}

A cultura empreendedora difundida atualmente no país tem, no segmento de jovens pertencentes à classe média, um terreno fértil, que vem, nos últimos tempos, captando ideais liberais que valorizam a livre-iniciativa, e a

\footnotetext{
${ }^{1}$ Doutor em Administração pela FGV-SP. Professor Doutor do Programa de Pós-graduação em Administração da Universidade Federal de Mato Grosso do Sul (PPGAd/UFMS. Departamento de Economia e Administração-Av. Filinto Müller, 1555, CEP: 79074-460, Campo Grande/MS. Email: dolima@nin.ufms.br.

${ }^{2}$ Pós-Doutor pela Ecole Nationale des Ingenieurs et Techniques de Industries Agroalimentaires. Professor Doutor do Programa de Pós-graduação em Administração da Universidade Federal de Mato Grosso do Sul (PPGAd/UFMS. Departamento de Economia e Administração - Av. Filinto Müller, 1555, CEP: 79074-460, Campo Grande/MS.E-mail: drls@nin.ufms.br.

${ }^{3}$ Professor Doutorando em Ciência da Informação pela UnB, Mestre em Educação pela UFMT (2003) e graduado em Economia pela UFMT (1990). Bolsista do CNPq/CID/UnB. Email : eberluis@terra.com.br. Artigo recebido em: 26/10/2008. Aceito em: 12/04/2009. Membro do Corpo Editorial Científico responsável pelo processo editorial: Martinho Isnard Ribeiro de Almeida.
} 
autonomia em sua realização pessoal e profissional. Essa juventude da classe média, cuja formação é voltada ao trabalho na modalidade empreendedora, pode ser explicada por influências que objetivam uma intenção de reprodução e ascensão social também compatível às aspirações familiares.

No entanto, a maior parte dos jovens brasileiros tem pouca ou nenhuma cultura empreendedora. Uma das causas que contribuíram para isso foi o legado português expresso na forte submissão das relações entre a Coroa $e$ suas colônias. Barros e Prates (1996) apontam que 67\% dos trabalhadores brasileiros, de todos os níveis sociais, têm uma postura de espectadores, $77 \%$ apresentam uma postura de paternalismo e $76 \%$ mostram um comportamento de dependência. Esses fatos refletem na disposição dos jovens na busca de emprego 4 .

Outro ponto inibidor é o fato de o Estado brasileiro, historicamente, ter pouco se preocupado com a cultura do empreendedorismo, o que reflete na insuficiência de políticas públicas para esse fim. Mais recentemente, o Banco Nacional de Desenvolvimento Econômico e Social (BNDES) tem oferecido, timidamente, linhas de crédito para iniciativas empreendedoras. Outra iniciativa do estado refere-se à Lei Geral da Micro e Pequena Empresa que se encontra em tramitação no Congresso Nacional.

A doutrina religiosa brasileira, calcada secularmente no catolicismo romano, enraizou uma cultura contra-capitalista, contribuindo para a formação de um comportamento de servidão, e obediência, e de uma visão distorcida da acumulação de capital. Max Weber, no início do século passado, mostrou a relação entre a doutrina calvinista protestante e o surgimento do capitalismo na Europa (WEBER, 1987).

Este estudo analisa a percepção de jovens empreendedores sobre os fatores determinantes de sua cultura empreendedora, tais como a família, a escola, a formação complementar e a rede de relacionamento. Esses jovens são egressos de cursos na área de empreendedorismo oferecidos pelo Instituto Euvaldo Lodi (IEL), vinculado às federações de indústrias de todo o país.

${ }^{4}$ Uma discussão sobre os traços culturais organizacionais e dos brasileiros pode ser vista, respectivamente, em Motta, F. C. P.; Caldas, M. P. (1997); DaMatta, R. (1984). 
Dario de Oliveira Lima-Filho • Renato Luiz Sproesser • Eber Luis Capistrano Martins

\section{Contexto Teórico}

\subsection{O Mundo do Trabalho e o Liberalismo Econômico}

Assiste-se, hoje, a transformações importantes no mundo do trabalho. Novas formas de organização aparecem e sua natureza se modifica. Observa-se o desaparecimento de empregos permanentes e, simultaneamente, aparecem novas tecnologias e formas inovadoras de organização do trabalho.

Para Sennett (2000) estão acontecendo mudanças estruturais no mercado de trabalho e, por sua vez, provocam alterações no psicológicocomportamental da sociedade. Historicamente, o capitalismo cresceu aproveitando da relação capital-trabalho, sendo que a solução emprego $e$ assalariamento quebra o status quo da relação entre mão de obra e capital.

Nesse contexto, é preciso apontar aos jovens e à própria economia brasileira formas alternativas de inclusão econômica, já que o emprego formal deixa de ser o referencial para a ocupação profissional. Filion (1999) mostra sua preocupação com o fato de a sociedade precisar entender que o mundo do trabalho mudou e que as gerações que estão chegando à fase de iniciação profissional não estão devidamente conscientizadas disso.

Morin (2001, p. 9), em seu estudo sobre os sentidos do trabalho na vida dos indivíduos e organizações, assegura que "[...] ao mesmo tempo em que milhares de pessoas sofrem pela falta de uma vaga de trabalho, outras sofrem pelo fato de terem que trabalhar excessivamente". Observa-se que o resultado prático da nova ordem mundial tem sido uma sociedade mais competitiva e individualista. Os indivíduos estão cada vez mais isolados e estressados. São pessoas desenraizadas, sem pertencimentos. Em uma sociedade onde indivíduos privilegiados competem em grupos seletos, e muitos excluídos vagam e migram em diferentes posições na estrutura produtiva, não há, para estes últimos, mais oportunidades no mercado de trabalho (GOHN, 2001; POCHMANN, 2002).

O quadro das influências neoliberais no mundo do trabalho caracteriza-se por uma realidade em que os indivíduos dedicam-se mais ao trabalho e tendem a ser menos sensíveis a questões sociais e de formação do caráter. São pessoas que passam a maior parte de sua vida dentro da empresa. Desenvolvem suas atividades em um contexto em que a competição individual e flexibilidade dos contratos são presentes. O individualismo, como uma das características da identidade liberal, fica ressaltado na sociedade. O trabalho, 
assim, é tido como necessidade de sobrevivência em primeiro lugar. O prazer de se trabalhar vem sendo deixado de lado pelo indivíduo no contexto neoliberal (POCHMANN, 2002).

Questões emergentes decorrentes do neoliberalismo, que impactaram o mercado de trabalho, devem ser observadas nas características que influenciam as famílias, particularmente aquelas de classe média, cujos membros foram educados para o mundo do labor, sob a forma de emprego. A globalização da economia, impulsionada pela dinâmica do capitalismo, contribuiu para o ressurgimento de correntes fundadas no pensamento neoliberal no último quarto do Século XX.

As características do emprego mudaram e a sociedade ainda está em busca de um melhor entendimento dessas mudanças, vivenciando realidades tais como o movimento liberal pró-empreendedorismo. O empreendedorismo, visto por alguns apenas como uma saída para o desemprego que assola as economias capitalistas, ainda deve ser melhor entendido na sociedade capitalista.

No entanto, o emprego "tradicional" ainda continua nos planos dos jovens brasileiros. Pesquisa realizada por Martins, Pereira e Lima-Filho (2003) mostra que, apesar de $63 \%$ dos alunos do curso de Administração de uma Instituição Federal de Ensino Superior (IFES) desejarem ter um negócio próprio, mais de $60 \%$ planejam buscar um emprego. Na Europa, segundo Klapper (2004), isso não é diferente, ou seja, recém graduados de uma escola de negócios da França almejam empregar-se em uma grande empresa, pois foram formados com esse objetivo. As razões apontadas para a não escolha do caminho do empreendedorismo são: baixa idade e falta de experiência profissional.

Também Robertson et al. (2003) mostram que, no Reino Unido, 22\% dos estudantes universitários não querem iniciar um negócio por falta de novas ideias ou oportunidades, tidas como vitais no empreendedorismo.

\subsection{Sociedade e Empreendedorismo}

Segundo Filion (1999), o empreendedorismo como campo de estudo acadêmico é novo, com cerca de duas décadas. Considera-se que está em fase pré-paradigmática e que demandará, ainda, algum tempo para constituir uma base científica, apesar de ser um campo efervescente em termos de pesquisas e publicações. 
Dolabela (1999) ressalta a importância do empreendedorismo no contexto de inovação e desenvolvimento dentro da sociedade. Para ele, o aumento da capacidade empreendedora de uma sociedade não se dá em função da retração no nível de emprego, mas como decorrência direta dos novos padrões de relações sociais e políticas. Existem transformações que estão acontecendo em sociedades desenvolvidas, inclusive da sua elite, particularmente no que se refere à mudança de valores, num sentido de compreensão do papel do indivíduo empreendedor como modelo na escala social.

No contexto de liberalismo econômico, a questão que se coloca é: até que ponto pode-se acreditar que as ações da cultura empreendedora na comunidade poderão diminuir as consequências sociais causadas pelas alterações estruturais no mundo do trabalho?

Para Drucker (1986), o empreendedorismo pode ser um importante ponto na história das relações entre o indivíduo e a comunidade. Como defensor de uma sociedade empreendedora, Drucker conduz ao entendimento de que a inovação e o espírito empreendedor são necessários, tanto na sociedade quanto na economia; tanto no serviço público quanto nas empresas privadas. Trata-se, portanto, de algo maior do que uma simples forma de geração de emprego.

Ao acreditar que o empreendedor vê a mudança como norma e sadia, seus defensores, como Drucker (1986) e Dolabela (1999), acreditam que o seu papel e sua importância são, hoje, reconhecidos pelas diversas ciências que tratam o desenvolvimento humano social.

Dolabela (2001) afirma que o empreendedor assume características que podem servir à comunidade, não apenas no campo empresarial como o senso comum relata. Ele atua numa perspectiva social de envolvimento da sociedade em iniciativas pró-ativas, que impactem o desenvolvimento de ações $e$ atividades. $\mathrm{O}$ conceito do empreendedor, enquanto forma de ser, atua num sentido de estimular a comunidade em sua auto-realização e felicidade por meio do trabalho e da assistência à sociedade.

Assim, há muitas formas de empreender. Cada um poderá escolher a sua ou até passar de uma para outra. Para Filion (2000), o leque das opções vai da empresa familiar ao trabalho autônomo, das empresas cooperativas ao empreendedorismo social (o chamado terceiro setor, sem fins lucrativos), além das inúmeras possibilidades geradas pelas grandes corporações com a terceirização. 
Dolabela (1999) explica um dos motivos dessa diversidade no campo de atuação do empreendedor ao relatar que o empreendedorismo oferece graus elevados de realização pessoal. Associa a atividade empreendedora com o trabalho feito com prazer. O indivíduo, ao empreender, está à procura de sua autorrealização, do seu reconhecimento social, de sua expressão enquanto ser humano livre e realizado com o que produz, e não como indivíduo centrado em atividades que não lhe garantem sua autovalorização.

Para os defensores do empreendedorismo na sociedade, tal como Drucker (1986), não se pode ser omisso na educação dos indivíduos para que inovem, para que sejam criativos e para que busquem o crescimento e a mudança na maneira de entender o valor do trabalho.

\subsection{Educação e Formação de Empreendedores na Sociedade}

Algumas considerações são feitas frente ao crescimento da educação para o empreendedorismo no Brasil. A primeira diz respeito ao cenário econômico-social nas últimas décadas no país, traduzido pelo crescimento populacional contrastado pela estagnação ou baixo crescimento na oferta de emprego e na geração de renda. Essa situação fomenta, em parte, maior interesse da sociedade na abertura de micro e pequenas empresas, ou seja, interesse econômico pelo empreendedorismo mais pela necessidade de sobrevivência do que pelo aproveitamento de oportunidades.

No relatório executivo de 2002 do Global Entrepreneurship Monitor (GEM, 2002), coordenado pela London Business School, da Inglaterra, e pelo Babson College, dos Estados Unidos, o Brasil aparece com mais de 14,4 milhões de pessoas envolvidas em alguma atividade empreendedora de negócios. Ou seja, um em cada sete brasileiros da população economicamente ativa estava empreendendo, fato que coloca o país em sétimo lugar na classificação mundial. Esse relatório sugere que o crescimento do número de empreendedores no país deve ser melhor tratado pela sociedade, ampliando-se sua base de disseminação e estratégias de fortalecimento da capacidade empreendedora, particularmente via processos educacionais que promovam no indivíduo sua melhor condição de competitividade no mundo liberal e globalizado.

Existe a necessidade de instituições que deem suporte educacional a essa crescente demanda. O papel da educação não formal e voltada ao trabalho faz-se necessário nesse contexto de interesse da sociedade pelo 
empreendedorismo. É o ambiente neoliberal forçando a sociedade em busca de alternativas no mundo do trabalho, que não sejam aquelas historicamente tradicionais, tal como o emprego formal.

Com programas e ações visando à formação de empreendedores, o Brasil entrou no novo milênio com potencial para desenvolver o ensino de empreendedorismo, a exemplo dos Estados Unidos, onde mais de 1.100 escolas já o fazem (CIELO, 2001). Todavia, o universo de instituições disseminadoras do empreendedorismo no Brasil ainda é pequeno, ressaltando-se as atuações de algumas Instituições de Ensino Superior (IES), do Serviço Brasileiro de Apoio às Micro e Pequenas Empresas (SEBRAE), do IEL e de algumas associações empresariais que atuam em várias regiões do País.

Uma segunda questão a ser considerada, em relação ao desenvolvimento da educação para o empreendedorismo, é a percepção que se deve ter sobre as necessidades de conhecimento em que se assentam os empreendedores. Para se formar empreendedores, é preciso conhecê-los melhor, inclusive seus valores e processos de aprendizagem, para que favoreçam seu crescimento.

Estudos de empreendedores (FILION, 1999; DOLABELA, 1999; LUCAS; COOPER, 2004) demonstram que algumas características fundamentais podem ser identificadas em qualquer segmento da população: iniciativa, autoconfiança, otimismo, necessidade de realização, coragem, forte intuição, comprometimento, orientação para metas e resultados, trabalhadores incansáveis, sonhadores realistas, racionais, líderes, orientados para o futuro, cultivam imaginação, definem visões, pragmáticos, flexíveis, inovadores, criativos, aceitam desafios e administram riscos moderados.

As características que compõem a personalidade do empreendedor são comuns a todos os indivíduos. Em alguns, essas características estão mais pronunciadas do que em outros. Contudo, é possível formar empreendedores, dotando-os de algumas ferramentas básicas para o desenvolvimento de suas ideias (CIELO, 2001).

Filion (1999) assegura que estratégias educacionais que promovam o empreendedorismo devem considerar que não se pode ensiná-lo como se ensinam outras matérias. É possível conceber programas e cursos como sistemas de aprendizado adaptados à lógica desse campo de estudo. A abordagem deve levar o aluno a definir e estruturar contextos e compreender várias etapas de sua evolução. 
Há que se considerar, portanto, que tanto no papel da educação formal quanto da educação não formal, os interesses pelo aprendizado mais utilitarista estarão sempre presentes face, sobretudo, às necessidades de conhecimento do empreendedor.

Grun (2002) mostra que não existe, necessariamente, ligação entre o nível de aprendizado escolar e o sucesso dos negócios. Todavia, a complexidade imposta, atualmente, no mundo da competitividade neoliberal, exige um novo tipo de empreendedor, preparado para enfrentar os desafios que lhe são impostos diariamente, dentro de novos conceitos de cooperação nacional e global (LIMA-FILHO; SPROESSER, 2006).

Lezana e Tonelli (1998) também destacam a importância da escolaridade, uma vez que o empreendedor deve possuir um nível mínimo de educação formal, que lhe permita tratar, de modo satisfatório, com as pessoas, além de ter condições de entender e interpretar a realidade. Aliado à escolaridade, é imprescindível ao empreendedor ter formação complementar, aquisição de conhecimentos novos ou atualização dos que já possui, a partir de interesse particular ou de necessidade gerada pelo negócio.

Deve-se considerar que, para se desenvolver uma pedagogia empreendedora, o entendimento das necessidades dos empreendedores passa a ser uma questão fundamental. É importante compreender que instituições que disponibilizam formação na área do empreendedorismo estão voltadas a atender ao caráter de desenvolvimento do indivíduo, de modo que consiga enfrentar, com profissionalismo, a realidade que lhe é imposta.

Avaliando os objetivos e conteúdos de alguns cursos ofertados por IES brasileiras, a exemplo da Fundação Getúlio Vargas e da Universidade de São Paulo, e por entidades representativas empresariais, como o SEBRAE e o IEL, parece ficar evidente nas metodologias pedagógicas o caráter de fortalecer o indivíduo no que tange à iniciativa e à competência empreendedora.

De fato, essas instituições colaboram para a formação do empreendedor na sociedade, particularmente após ele ter concluído seu processo de escolarização formal e, sobretudo, se encontra diante do desafio de procurar um emprego ou empreender autonomamente. 
Dario de Oliveira Lima-Filho • Renato Luiz Sproesser • Eber Luis Capistrano Martins

\subsection{A Importância da Família na Formação Pró- empreendedorismo}

Na vida de empreendedores, além dos aspectos da sua formação, escolarização, habilidades, conhecimentos, valores, atitudes, contexto sócioeconômico, deve-se considerar, também, o contexto familiar, ou seja, a influência que a família exerce sobre o desenvolvimento do potencial empreendedor. O contato com o ambiente familiar, da escola, de amigos, do trabalho e da sociedade possibilita o desenvolvimento de algumas características de personalidade e talentos e, ao mesmo tempo, pode bloquear e enfraquecer outros (PATI, 1995). Esse processo ocorre ao longo da vida dos indivíduos por meio das circunstâncias com as quais se deparam e que fazem parte de sua história.

A trajetória profissional dos pais, principalmente quando bem-sucedida, de alguma forma influencia a dos filhos, levando-os a seguirem o mesmo caminho. Por outro lado, embora haja alta probabilidade disso ocorrer, há casos em que a influência ocorre no sentido oposto, e os filhos evitam, deliberadamente, seguir o caminho dos pais (OLIVEIRA, 1995).

A importância da trajetória familiar para o desenvolvimento do empreendedorismo é reforçada por Dolabela (1999), quando ele sugere que a marca da família constitui uma referência, um ponto de partida que o empreendedor considera. Em muitos casos, permanece nos negócios da família implementando mudanças; em outros, apenas permanece no mesmo ramo de negócio, sem ser especificamente no mesmo negócio da família.

Outro aspecto a ser abordado no contexto familiar, que propicia o surgimento de empreendedores, são as chamadas diretrizes psicológicas, ou seja, os comportamentos e atitudes absorvidas pelas crianças por meio dos pais e demais pessoas com as quais convivem (FILION, 1999). Nesse sentido, Oliveira (1995) revela que não bastam apenas as palavras, mas é preciso ter uma postura que demonstre aos filhos, desde pequenos, como enfrentar a vida, o trabalho $e$ as relações pessoais. É possível que empreendedores tenham recebido, na infância, mensagens apontando para a crença de que teriam de lutar por tudo que quisessem conquistar na vida.

Autores como Dolabela (1999), Filion (1999) e Oliveira (1995) são unânimes em afirmar que a marca da família constitui uma referência considerada pelo empreendedor tanto de forma direta - seguindo no mesmo ramo 
de negócio dos pais - ou de forma indireta - consciência adulta precoce, existência de cenas primais, diretrizes psicológicas e outras.

\subsection{Estratégias de Famílias de Empresários para Encaminhar os Jovens para o Mundo dos Negócios}

Como a classe média esteve durante muito tempo voltada a influenciar seus filhos para o mundo do emprego, interessa compreender um pouco mais sobre o segmento de famílias dessa classe que optou pela formação empreendedora para seus jovens.

Algumas questões se apresentam com maior ênfase no entendimento das estratégias educacionais e de reprodução social em famílias de empresários: (a) a iniciação precoce no mundo dos negócios influenciando na formação dos jovens; (b) o quadro envolto na relação sucessão familiar e seus jovens; $e$ (c) a seleção do tipo de escola.

Nogueira e Almeida (2002), em estudo sobre a escolarização de famílias de empresários, revelam que a influência dos pais na formação do jovem objetiva sua reprodução social. Em alguns casos, o processo de formação do jovem, filho de pais empresários, assume interesses aos quais ele figura apenas como um coadjuvante nas intenções da família (GRUN, 2002). Em relação à iniciação no mundo empresarial de jovens filhos de empresários, Nogueira e Almeida (2002) asseguram que a experiência nos negócios é feita, basicamente, em empresas familiares. Em alguns casos, o jovem tem sua iniciativa profissional nas atividades mais operacionais e vai galgando postos de trabalho mais elevados, sob o argumento de que isso é bom "para aprender" e conhecer o funcionamento global de um estabelecimento; em outros, começa assessorando a diretoria.

Evidencia-se, como expressão da necessidade de primazia dos interesses familiares sobre os individuais, que a iniciação precoce trabalha pela formação de vocações para o mundo dos negócios, podendo ser, em alguns casos, originados de fatores culturais de etnias (GRUN, 2002; DOLABELA, 2000).

Famílias de empresários utilizam-se, ainda, de estratégias de formação de sucessores no contexto de inserção do jovem no mundo do trabalho. A sucessão familiar começa muitos anos antes, quando os filhos ainda são pequenos. Ao longo do extenso caminho, que separa a infância do momento de iniciação profissional, muitas medidas são tomadas para a formação da 
base e o plano de desenvolvimento sucessório na empresa familiar. A sucessão familiar inicia-se pela formação de valores pelo trabalho.

As questões de iniciação precoce e o processo de sucessão familiar influenciam na formação do jovem oriundo de família de empresários, projetando uma aparente espiral em que a educação e o mundo do trabalho se envolvem, objetivando possibilitar uma ascensão social. Grun (2002) afirma que a educação formal na escola é encarada como um meio para assegurar a reprodução social.

Existe, também, uma preocupação, por parte dos pais empresários, em escolher para os filhos estabelecimentos de ensino que propiciem a constituição de uma rede de sociabilidade predisposta a funcionar, no presente $e$ no futuro, como capital social. A escola passa ser um importante agente a ser utilizado pela família para fomento de valores empreendedores. O que parece preponderar, no caso das famílias de empresários, no ato de escolha da escola, é menos o valor acadêmico e mais seu valor social. De fato, a escolaridade dos filhos desse segmento se desenrola, muitas vezes, do ensino fundamental ao superior na rede privada de ensino, seguindo uma orientação familiar (NOGUEIRA; ALMEIDA, 2002).

Existe a necessidade de se considerar os múltiplos critérios de hierarquização social vigentes na sociedade brasileira, $e$ as maneiras por meio das quais o sistema escolar acaba sendo relativizado ou controlado na busca de opções para as famílias conduzirem suas estratégias de reprodução social, para encaminhar as novas gerações a destinos por elas desejados, ainda que considerados poucos legítimos na sociedade tradicional (GRUN, 2002).

Todavia, essas estratégias educacionais de famílias de empresários consideram que o jovem aceite se submeter a tais interesses empreendedores. Nesse sentido, é necessário que o "herdeiro" aceite a "herança" (BOURDIEU, 2003). Tais considerações apontam que a inserção do jovem no mundo do trabalho absorve interesses familiares, que se sobrepõem ao próprio interesse individual do jovem. A condição do ambiente familiar empreendedor, as falas, os comportamentos, as atividades, os exemplos dos pais, acabam por inserir no jovem aspectos condicionantes em sua formação de valores.

Quando a família opta por estabelecer critérios de escolha da escola para seus jovens e, também, quando decide promover a sucessão familiar, está corroborando o processo de formação para o empreendedorismo.

Por outro lado, o papel da escola fica colocado como um local de valorização do ser social, ou seja, dos relacionamentos, das amizades e do conví- 
vio em camadas sociais mais homogêneas possíveis, satisfazendo as necessidades procuradas pelas famílias de empresários.

Resta entender como os jovens percebem a pressão no mundo do trabalho em um ambiente de liberalismo econômico e, ainda, a influência familiar para o trabalho. Quais reações e características pessoais são assumidas pela juventude, dentro desse contexto?

\section{Metodologia}

O empreendedor aqui é tomado no sentido amplo de proprietário-gerente. Não se considerou, neste estudo, os empreendedores sociais, os intraempreendedores, os trabalhadores autônomos e as cooperativas.

Para que se possa compreender e atingir o objetivo da pesquisa, propõe-se caracterizar o jovem empreendedor, egresso de programas de empreendedorismo, identificando aspectos influenciadores em seu processo de formação para o empreendedorismo.

A escolha de uma categoria ocupacional e socioeconômica recaiu sobre jovens empreendedores em atividades de manufatura, varejo e outros serviços, da cidade de Cuiabá-MT. Essa escolha obedeceu, fundamentalmente, a delimitação de um grupo com contornos definidos, identificados mediante critérios objetiváveis, facilitando, assim, a composição e a relativa homogeneidade dos sujeitos.

Neste estudo, os parâmetros para a definição de jovem consideram a categoria etária tida como jovem-adulto, aceitando a faixa entre 22 e 34 anos, buscando o entendimento do processo de formação do empreendedor. As questões dos jovens que interessam nesta investigação repousam sobre aquele segmento que aceitou o trabalho via empreendedorismo de negócios como uma alternativa de desenvolvimento pessoal e profissional.

O jovem empreendedor escolhido para este estudo é oriundo da classe média. De acordo com Ferrari (1982), uma das características da classe média é que ela está sempre em movimento em busca de posicionamento em classes superiores à sua.

Para Ferrari (1982, p. 422), os jovens

[...] mobilizam-se para atingir a classe alta e encontramse nesse estrato por motivos estruturais. Ideologicamente 
Dario de Oliveira Lima-Filho • Renato Luiz Sproesser • Eber Luis Capistrano Martins

dividem-se em uma maioria 'conservador'a e pequenos grupos intelectuais 'revolucionários'; consideram a educação universitária de que são portadores como 'canal de ascensão social'; vivem em casas próprias e procuram imitar os padrões da classe alta.

Essa caracterização mostra-se adequada para classificar os entrevistados como componentes da classe média, visto que possuem renda na faixa entre 15 e 25 salários mínimos, escolaridade superior e acreditam na ascensão social pela educação.

Os depoimentos foram divididos em dois blocos que destacam, primeiramente, as características gerais do jovem empreendedor, os aspectos influenciadores em sua formação para o empreendedorismo e sua percepção em relação à contribuição da escola e da família na sua formação. Foram realizadas entrevistas temáticas, englobando aspectos sugeridos por Alberti (1989), Queiróz (1987) e Minayo e Deslandes (2002).

A seleção dos entrevistados foi considerada a partir dos históricos de matrícula nos cursos na área de empreendedorismo, em nível de especialização (carga horária mínima de 360 horas-aula), entre os anos de 1998 e 2002. Buscaram-se aqueles empreendedores, conforme caracterizado por Filion (2000), que tivessem negócios na região e residência em Cuiabá há, pelo menos, cinco anos. Foram seguidas as orientações de Alberti (1989) em relação à seleção dos entrevistados.

Ainda segundo Alberti (1989), somente durante a execução das entrevistas é que o número delas pode ser melhor definido, pois é conhecendo as fontes de investigação que os pesquisadores adquirem experiência para avaliar a adequação do conteúdo já obtido aos objetivos do estudo.

Trinta egressos foram convidados a participar deste estudo, dos quais 16 entrevistas foram efetivadas. Foi admitido o princípio da saturação, no tamanho da amostra final, conforme recomendado por Griffin e Hauser (1993).

Alguns pesquisadores têm se baseado no princípio da saturação para pesquisas exploratórias. Segundo Alberti (1989, p. 19),

[...] pode ser útil recorrer ao conceito de 'saturação', formulado por Daniel Bertaux. De acordo com este autor, há um momento em que as entrevistas acabam por se repetir, seja em seu conteúdo, seja na forma pela qual se constrói sua narrativa. Quando as diversas entrevistas em uma 
pesquisa de história oral começam a se tornar repetitivas, continuar o trabalho significa aumentar o investimento, enquanto o retorno é reduzido, já que se produz cada vez menos informação. Este é o que o autor chama de ponto de saturação, a que o pesquisador chega quando tem a impressão de que não haverá nada de novo a aprender sobre o objeto de estudo, se prosseguir as entrevistas.

Nesse sentido, a partir da décima quarta entrevista, o princípio da saturação foi evidenciado. Das 16 entrevistas, dez foram realizadas no próprio local de trabalho dos entrevistados, a pedido deles. Apenas seis entrevistados preferiram outros locais. O tempo médio das entrevistas foi de 50 minutos cada, utilizando-se da técnica de uso do gravador e caderno de anotação de campo.

\section{Resultados}

\subsection{Características Gerais dos Jovens Empreendedores}

Os jovens empreendedores entrevistados apresentaram idade média de 28 anos, sendo que $50 \%$ deles são do sexo masculino. Essa igualdade percentual relativa ao gênero dos atores sociais entrevistados não foi intencional e nem objetivada. As entrevistas desenvolveram-se seguindo a busca do princípio da saturação.

Dentre suas características gerais, observa-se que $80 \%$ deles consideram-se migrantes, que vieram para Mato Grosso (MT) acompanhando suas famílias. Os dados coletados apontaram que quatro deles vieram da Região Sul, cinco da Região Sudeste, dois são do interior de MT e outros dois são de Mato Grosso do Sul. Apenas três jovens, dentre os 16 entrevistados, nasceram em Cuiabá-MT.

Este grupo de jovens empreendedores participantes dos programas de empreendedorismo do IEL são proprietários-gerentes de empresas em CuiabáMT, tal como define Filion (2000), sendo que 50\% deles são empreendedores do setor comercial, $40 \%$ são do setor de serviços e $10 \%$ do setor industrial.

O tempo médio de atuação como empreendedor é de quatro anos para o grupo. Todavia, destaca-se que 11 , dos 16 jovens empreendedores entrevistados, estão na faixa entre dois e cinco anos de atuação no mundo empre- 
sarial. Esse período normalmente é tido como crítico, pois a pressão sobre o empreendedor é intensa sob todos os aspectos.

Segundo relatório executivo do Global Entrepreneurship Monitor-2002 (GEM, 2002), a participação da empresa de estrutura familiar alcança mais de $50 \%$. No presente estudo, verificou-se que $55 \%$ dos jovens empreendedores possuem empresas de criação própria e $45 \%$ são oriundos de empresas tipo familiar.

Uma das características que emergiu nesse grupo de jovens empreendedores foi o fato de 15 deles serem de origem de família de empresários. Essa condição familiar empreendedora é comprovada, ao se considerar que apenas um entrevistado afirmou que seus pais são funcionários públicos.

A sugestão de Nogueira e Almeida (2002), de que a família de empresários direciona seus filhos para escolas da iniciativa privada, emerge nesse grupo de jovens empreendedores analisados. Identificou-se que 11 jovens empreendedores entrevistados cursaram o ensino fundamental e médio na rede escolar privada; além disso, $75 \%$ deles fizeram curso superior em IES privada.

Em relação ao ensino fundamental, a maior parte dos jovens entrevistados estudou em colégios tradicionais, sendo todos vinculados a instituições religiosas. No ensino médio, a maioria desse grupo de jovens empreendedores estudou em escolas aristocráticas. Trata-se de escolas onde a sociedade cuiabana encaminha seus filhos em busca da melhor relação ensinoqualidade, combinando, ainda, com aspectos de relacionamento social.

A respeito do ensino superior, verifica-se nesse grupo de jovens empreendedores, que $50 \%$ deles estudaram em instituições privadas consideradas ainda novas, pois algumas tinham, na época, menos de dez anos de atuação no mercado. Todos os jovens empreendedores, que estudaram nessas instituições de ensino superior, foram em busca do curso de graduação em administração de empresas. Aqui ressalta-se o que Grun (2002) verificou em seu estudo com famílias de empresários, o que coloca a questão de o jovem não investir esforços em uma educação que o leve a procurar outros caminhos, senão aqueles objetivados pela família. Essas instituições, à época escolhidas por esses jovens empreendedores, eram também iniciantes em seus processos de formação e com pouco acúmulo de experiência, tendo pouca credibilidade no mercado da educação local.

O fato de terem origem em famílias de empresários contribuiu, também, para aquilo que Nogueira e Almeida (2002) revelam em relação à graduação em nível superior estar em área correlacionada ao mundo empresa- 
rial. Isso fica claro pois 13 dos entrevistados fizeram cursos nas áreas vinculadas à administração de empresas e três cursaram engenharia e informática.

\subsection{Ser Empreendedor e o Sucesso Profissional}

Afinal, o que é ser empreendedor para esse grupo de jovens egressos de cursos de especialização em gestão de negócios? Buscou-se entender como o grupo vê o conceito do que faz, ou seja, entender sua percepção do ser empreendedor, a qual reflete em sua forma de agir dentro da sociedade, embutida por suas necessidades, conhecimentos e valores.

Nos relatos coletados observou-se que a autorrealização, o reconhecimento pessoal e a coragem para montar um negócio ressaltam nas entrevistas como características de um empreendedor. Por serem oriundos, em sua maioria, de famílias de empresários, assimilaram a busca de necessidades como aumento da autoconfiança e desenvolvimento de suas habilidades, como sugerem Lezana e Tonelli (1998).

Os depoimentos levam a entender que, em sua maneira de agir, consideram valores característicos de um empreendedor, tais como ter em suas mãos seu futuro profissional e busca da maior competitividade. Esses valores são assimilados na sua trajetória de vida, influenciado principalmente pelo ambiente de convivência, tais como citados por Filion (1999) e Farrel (1993).

A defesa do ser empreendedor e sua importância na sociedade aparecem nos discursos dos jovens entrevistados, firmada, principalmente, na necessidade de auxiliar outras pessoas e gerar empregos. Os depoimentos apontam que o jovem empreendedor, mesmo na sua ótica capitalista de resultados econômicos, se congratula com o fato de poder gerar renda e melhoria na qualidade de vida de outras pessoas.

Alguns depoimentos reforçam que o jovem empreendedor, em suas ações, está buscando sua realização pessoal. Longen (1997) e Lezana e Tonelli (1998) caracterizam a realização pessoal do empreendedor como uma necessidade para empreender, motivando-o ao trabalho. $\mathrm{O}$ autoconhecimento, a conscientização das próprias necessidades e o entendimento de seus comportamentos, atitudes e desejos farão com que o indivíduo consiga, mais facilmente, alcançar seus objetivos e elevar sua motivação (LEZANA; TONELLI, 1998).

Para Lezana e Tonelli (1998), a necessidade de autorrealização do empreendedor é o motor do crescimento, pois permite que ele maximize seu potencial na tentativa de superar os próprios limites. A conscientização de 
Dario de Oliveira Lima-Filho • Renato Luiz Sproesser • Eber Luis Capistrano Martins

suas limitações possibilita o desenvolvimento de novas habilidades, assim como a busca por novos conhecimentos.

Verificou-se, em algumas entrevistas, que um dos fatores impulsionadores do empreender, no discurso desse grupo de jovens empreendedores, é a necessidade de reconhecimento daquilo que vem realizando na sociedade.

Sheedy (1996) comenta sobre a necessidade de aprovação que os empreendedores têm. Seus desejos de conquista de uma alta posição na sociedade, de reconhecimento, do respeito, do status e do prestígio da sociedade, caracterizam esta necessidade de aprovação.

A característica de pertencerem à classe social média, acreditando na possibilidade de ascensão a uma classe superior, se apresentou no contexto das entrevistas com esse grupo.

Lezana e Tonelli (1998) reforçam que o desenvolvimento de um empreendimento depende, principalmente, da figura central do empreendedor. Se as necessidades são as grandes impulsionadoras dos comportamentos, um empreendedor se move, dentre outros fatores, pela busca de melhoria nas condições de sua vida social.

\subsection{Prazer e Empreendedorismo}

Ao acreditarem em seu potencial de realização, ao buscarem o reconhecimento $e$ a ascensão social, os jovens trabalham e dedicam-se muito à empresa. Alguns depoimentos desse grupo de jovens empreendedores demonstraram que são dedicados ao trabalho porque gostam do que fazem.

Dornelas (2001) afirma que os empreendedores são, entre outras características: determinados, dinâmicos, dedicados, otimistas e apaixonados pelo que fazem. Ao estarem empreendendo, esses jovens empreendedores declararam que existe dificuldade em controlarem-se diante da quantidade de atividades em seu trabalho. Sua preocupação com o labor lhes toma considerável tempo de dedicação; a busca de suas necessidades se traduz em intensa dedicação à empresa, de onde ele espera poder colher frutos e satisfações pessoais em sua trajetória de vida.

As considerações teóricas de Sennett (2000) e Handy (2001) apontam que o indivíduo em descompasso e sem equilíbrio na sua relação objetivo de vida, tempo e trabalho, acaba por colher consequências pessoais negativas, desorientando seu futuro profissional. Ao empreender, acredita-se que 
o indivíduo esteja aceitando desenvolver suas potencialidades através do trabalho que lhe possibilita uma maior motivação e desafio para sua vida.

A aceitação desse grupo de jovens entrevistados, em relação à pressão para o mundo do trabalho, esteve realçada. A flexibilidade de ação e de carga horária, os interesses familiares, combinados com seus valores e necessidades enquanto indivíduos são elementos constantemente presentes no universo do jovem empreendedor.

Sem tempo para si, a maioria dos entrevistados mostrou, também, certa preocupação com o bem-estar e com o relacionamento familiar, visto sua relação conflitante com o tempo dedicado ao trabalho e o tempo dedicado à família.

Esse grupo de entrevistados, de origem da classe média, tem consigo o fato de receber uma gama de valores sociais, da família, da igreja, da escola $e$ de grupos sociais que refletem sua autocondenação ao abuso do tempo dedicado à empresa. Nada obstante, aqueles entrevistados que já constituíram famílias, inclusive com filhos, sentem mais essa pressão, do que o jovem empreendedor, solteiro e sem filhos. Alguns depoimentos vão contra aquilo que De Masi (2000) apregoa, ou seja, a necessidade do tempo livre, caracterizando o ócio criativo necessário para que o indivíduo encontre seu equilíbrio como ser humano.

Em alguns depoimentos verifica-se a necessidade de relacionamento social, como sendo um meio para diminuir a pressão do dia a dia da vida empresarial. Alguns declararam praticar algum tipo de esporte ou adotarem um hobby de final de semana.

Verifica-se, assim, certa preocupação com a qualidade de vida nesse grupo de jovens empreendedores da classe média. Os apontamentos de Handy (2001), Sennett (2000) e De Masi (2000) sobre a necessidade de dedicarem-se a outras atividades sociais é, em parte, compreendida por esses jovens.

\subsection{Educação e Busca de Conhecimento}

Para Dornelas (2001), os empreendedores são independentes e constroem seu próprio destino. São bons em planejamento, líderes e formadores de equipes, e são, sobretudo, sedentos por novos conhecimentos. 
Dario de Oliveira Lima-Filho • Renato Luiz Sproesser • Eber Luis Capistrano Martins

Para Lezana e Tonelli (1998), durante o processo de formação empreendedora, os conhecimentos são reforçados para suprir as necessidades de desenvolvimento pessoal dos empreendedores, desenvolvendo seus potenciais e habilidades por meio de novos conhecimentos, visando inovar e estar sempre acompanhando e à frente das mudanças exigidas pelo mercado.

Nota-se nos depoimentos que a conversa do dia a dia, para o empreendedor, é uma das formas mais utilizadas para assimilação de conhecimento. Dada a fragmentação do conhecimento obtido dessa maneira, esse jovem se utiliza também de outras formas, tal como a educação complementar.

Verifica-se, também, um relacionamento social do tipo utilitarista. Como são dedicados e profissionais valorizam o conhecimento e vivem seu empreendimento, é natural que esses jovens empreendedores busquem estabelecer relações que vinculem aprendizado utilitarista em seu modus operandi de empreendedor.

O jovem empreendedor que vive num mundo competitivo demonstra, pelos depoimentos coletados, a necessidade de busca de conhecimento também pela literatura e cursos do tipo utilitarista.

Mesmo que esses jovens valorizem o investimento em educação, observou-se que se utilizam de vários meios para assimilar o contexto de informação necessária para sua performance empreendedora. $\mathrm{O}$ aprendizado em sala de aula, via educação formal e formação complementar, é adicionada por leituras técnicas e relacionamentos pessoais.

Parece que a experiência pela prática é um valor considerado pelos jovens empreendedores na busca de conhecimento, ao referirem-se à necessidade de relacionamentos do tipo utilitarista. Aprendem muito com experiências de outras pessoas que dispõem de informações que contribuam para sua formação empreendedora.

\subsection{Educação Formal e Jovens Empreendedores}

As percepções dos jovens em relação ao valor da escola formal tradicional são assimiladas, principalmente, na formação como pessoa. Alguns jovens empreendedores declararam que a educação formal recebida nas escolas em que participaram teve influências positivas em seu desenvolvimento pessoal. 
Quase a totalidade deles estudou em escolas particulares, tanto no ensino fundamental como no ensino médio e superior. $\mathrm{O}$ fato de a maioria estudar em escolas administradas por religiosos, foi também ponto importante na transmissão de valores para sua formação.

Os depoimentos coletados demonstram que esses jovens obtiveram uma formação escolar tradicional, com inclinação para valorizar aquilo considerado normal em termos educacionais, de modo que facilitasse a entrada no mercado de trabalho, pela busca de emprego.

Filion (1999) afirma que, no contexto atual, a maioria das pessoas deve procurar emprego caso queira trabalhar, fato explicado pela formação pouco estimuladora quanto aos aspectos da livre iniciativa empreendedora.

Os depoimentos desses jovens empreendedores conduzem a uma reflexão de Dolabela (1999), que questiona a possibilidade do ensino voltado a formar empregados nos dias atuais. As percepções da influência para o empreendedorismo no ensino médio ficam, portanto, comprometidas nos discursos desse grupo de jovens entrevistados ao detectar que sua formação não foi diferente da maioria dos demais jovens de sua época.

Percebe-se, nos depoimentos, que o papel da universidade esteve mais voltado a estimular o grupo de jovens a ser empregado do que a ser empreendedor. Todavia, os depoimentos esclarecem que, comparado ao ensino médio, o ensino superior se aproxima de questões de maior interesse do grupo de jovens empreendedores, até mesmo pelas escolhas acadêmicas assumidas em administração de empresas.

Por decorrêcia de serem de família de empresários e por receberem sua influência, os depoimentos dos jovens confirmam aquilo que Nogueira e Almeida (2002) evidenciaram em seus estudos: 64\% dos jovens entrevistados optaram por faculdade cuja orientação dominante volta-se para um certo tipo de formação superior, aquela que prepara para o mundo dos negócios e para a gestão empresarial.

Evidencia-se nas falas que o ensino superior poderia ter contribuído em maior ênfase na formação empreendedora desse grupo de jovens, pois seus depoimentos sinalizam certo descontentamento com o que receberam, como formação, na universidade. 


\subsection{Influência da Família para o Empreendedorismo}

Em todos os depoimentos coletados, a presença familiar demonstrou ser muito importante no processo de formação desse grupo de jovens empreendedores. Para a maioria dos entrevistados o pai influenciou em maior peso na sua formação empreendedora, embora. a importância da mãe também tenha sido destacada.

Segundo Oliveira (1995), a importância do contexto familiar (pai e mãe) na formação para o empreendedorismo se baseia naquilo que se denomina de educação informal, ou seja, a proximidade, as discussões em família, os amigos empresários e a vivência, que conformam um quadro no qual o jovem absorve valores deste mundo de negócios e competitivo.

Não foi observado nenhum caso, nos depoimentos coletados, de pais que não influenciaram esses jovens para o mundo do empreendedorismo. Observou-se uma preocupação com o estudo formal e com a graduação em nível superior, valores característicos da classe média; por outro lado, a orientação para o emprego não ficou evidenciada nas entrevistas.

Percebe-se, nesse grupo de jovens empreendedores, o valor do investimento na educação promovida por seus pais. Verifica-se que os investimentos realizados nos jovens foram por eles destacados como importantes, ou seja, valorizam o que receberam dos pais e a visão que estes tiveram em relação à educação dos filhos.

Nos discursos desses jovens não emergiu nenhum contexto desmerecedor da educação formal, no sentido tal como citado por Nogueira e Almeida (2002), ou seja, ceticismo sobre o valor da educação escolar tradicional. Ressalta-se a não observância de declarações dos jovens salientando que seus pais não valorizavam ou não incentivavam a educação escolar do tipo formal.

Por outro lado, ao propiciar a iniciação precoce no mundo do trabalho, observou-se a educação familiar apontando para o desafio empreendedor. A convivência, desde pequenos, no mundo empresarial, emergiu nos depoimentos dos jovens empreendedores entrevistados, influenciados pela característica familiar empreendedora de sua maioria.

Sua trajetória empreendedora teve, portanto, contribuições decisivas da família, a qual se utilizou de estratégias, tais como aquelas citadas por Grun (2002) e Nogueira e Almeida (2002), de aproximação do jovem à realidade do mundo dos negócios. 
Observou-se nos depoimentos de sete jovens que sua iniciação no ambiente empresarial se deu entre 10 e 11 anos de idade. A convivência, desde cedo, com o mundo empresarial fica evidenciada, sobretudo, pelas características dos valores repassados pela origem empresarial de suas famílias.

Assim, ao se discutir a formação empreendedora de jovens, enfatiza-se a importância da experiência, da intimidade com o assunto e da necessidade de construir algo novo calcado em experiências que lhe sirvam de alicerce. Segundo Teles (2001), o processo de formação não está no vazio, não ocorre sem referências nem se dá quando as explicações são feitas com um vocabulário desconhecido para a pessoa. Nesse sentido, a convivência desde cedo no mundo empresarial corroborou decisivamente na formação de valores empreendedores.

Lodi (1987) aponta que as estratégias de famílias de empresários devem promover, desde cedo, valores e conhecimentos do mundo empresarial no jovem. A sucessão familiar fica evidenciada em alguns depoimentos desse grupo de jovens empreendedores. Quase a metade deles $(45 \%)$ vive $e$ atua em empresas familiares, e receberam desafios e responsabilidades de perpetuar aquilo iniciado por seus pais.

Esses jovens internalizaram aquilo que Bourdieu (2003) denomina de "o herdeiro aceitou herdar a herança", ou seja, o jovem empreendedor, nesse caso, aceitou apropriar-se dela. Especificamente, os interesses familiares em formar um sucessor ficam evidenciados nos depoimentos dos jovens entrevistados.

\section{Discussão e Considerações Finais}

Este estudo teve como objetivo analisar as características de um grupo de jovens empreendedores, assim como suas opiniões quanto à importância da família, da escola formal e da formação complementar em sua trajetória para o empreendedorismo. Para tanto, foi conduzida uma pesquisa junto a uma amostra de 16 jovens empreendedores da classe média, egressos de cursos de empreendedorismo, utilizando-se de entrevistas temáticas.

Os resultados revelam que os modelos de influência são de grande importância para explicar os comportamentos empreendedores. Dessa maneira, a maioria dos empreendedores se tornou empreendedor graças à influência de um modelo em seu seio familiar ou próximo; um modelo com o qual 
ele quis se identificar. Os empreendedores adquirem, então, uma cultura empreendedora pelo relacionamento e pela prática.

O discurso do jovem empreendedor é otimista, em sua maior parte, e o coloca como indivíduo cuja história de vida valoriza a independência no modo de agir e a necessidade de garantir seu futuro conduzindo seu próprio caminho.

Além disso, os dados mostram a aquisição de conhecimento do tipo utilitarista e buscam, nos relacionamentos pessoais, uma forma de aprenderem pela experiência dos outros. Seus discursos demonstram que o valor pela educação escolar na formação do caráter foi importante, todavia, a educação, como fomento ao trabalho empreendedor, esteve mais assentada nas propostas pedagógicas de instituições que atuam na formação complementar.

Ser empreendedor para eles é realizar aquilo que os motiva, é trabalhar em prol do reconhecimento social e da melhoria de vida via ascensão social. Segundo os entrevistados, o papel do empreendedor na sociedade é gerar emprego e ajudar as pessoas por meio daquilo que conseguiram, a partir da formação de uma cultura empreendedora que os possibilita, também, visualizar atividades empreendedoras.

Por outro lado, esses jovens empreendedores sentem as consequências do seu esforço de dedicação ao trabalho, principalmente quando se referem ao fato de não estarem junto da família o tanto quanto desejariam. Sentem, também, a necessidade de buscar equilíbrio entre corpo e mente, quando refletem sobre o fato de terem a intenção de investir mais tempo em si mesmos e usufruir da sociedade do lazer. A maioria dos jovens desse grupo direciona parte significativa do seu tempo ao trabalho na empresa, relegando a segundo plano o convívio social, o lazer e a prática desportiva.

Ao contrário do senso comum, o jovem empreendedor não se fez parecer amoral ou transgressivo; pelo contrário, foi detectada uma preocupação com a ética, a honestidade, a transparência nas relações com as pessoas. Sua base de formação, tanto familiar quanto escolar ou religiosa, valoriza a existência de uma preocupação com o não rompimento dos seus princípios éticos, quando da realização empreendedora. Por originarem-se da classe média, absorveram, além dos valores éticos, preocupação com o conhecimento acadêmico, ao continuarem seus estudos após a conclusão do ensino de graduação. Nesse sentido, esses jovens revelaram a importância de terem assimilado conhecimentos na área do empreendedorismo e gestão, motivandoos a continuarem em busca de realização de seus projetos futuros. 
Em sua formação acadêmica, esses jovens empreendedores são, em sua maioria, oriundos de escolas católicas, de ensino privada, denotando a questão de terem recebido valores cristãos. Destacam-se os colégios considerados como sendo da "aristocracia cuiabana", tidos pelos próprios jovens como os melhores em termos de professores e qualidade de ensino. Reconhecem que seus pais tiveram grande importância ao possibilitarem um estudo no ensino fundamental e médio considerado de qualidade. Nessas escolas, receberam pouca influência na formação para o empreendedorismo, visto tratarem de colégios que, no dizer dos entrevistados, direcionavam-nos para o mercado do emprego e para a escolha da melhor profissão e da melhor IES. Essas considerações também são reforçadas quando se analisam os depoimentos em relação ao ensino superior, que, para a maioria, teve o caminho na IES privada.

A questão da preocupação com a escolha da escola onde o jovem filho de empresário irá desenrolar sua vida estudantil parece ser ressaltada nos discursos desse grupo de jovens, caracterizando que as escolas selecionadas refletem status social capaz de possibilitar relacionamentos e contatos com segmentos de maior nível econômico. Os interesses familiares que possibilitassem um convívio social utilitarista, capaz de promover a ascensão social da família, estiveram presentes nesse grupo de jovens.

Esses jovens, por terem como característica sua determinação e a busca de projetos e objetivos de futuro, apresentam uma sistemática de busca de conhecimento que ultrapassa a educação escolar formal. Buscam seu aprendizado pelo convívio com outras pessoas e aplicam esse relacionamento em direção a construir o conhecimento necessário para atingir seus objetivos.

As entrevistas dos jovens empreendedores confirmam que a presença da família na construção de valores empreendedores foi marcante, tanto por meio do modelo de influência dos pais quanto no convívio, desde cedo, no dia a dia empresarial.

A maioria desses jovens é originária de famílias de empreendedores e de imigrantes de estados do Sul e Sudeste, os quais se apresentam como reflexos de seus interesses. Nesse sentido, o caminho empreendedor traçado pelos jovens esteve muito próximo daquilo que Filion (1999; 2000), Dolabela (2000; 2001), Oliveira (1995) e outros citam quando se referem ao processo de formação de empreendedores. A iniciação precoce, a sucessão familiar e o direcionamento escolar do tipo utilitarista são variáveis, colocadas nos discursos dos jovens empreendedores, que representam sua estrutura de base identitária. 
Assim, o processo de formação empreendedora foi influenciado mais pela família do que pelas demais instituições sociais, como a escola formal e a instituição religiosa. A educação formal apresentou-se como importante na formação geral do jovem empreendedor, na forma de retenção de conhecimento e no estímulo ao desenvolvimento pessoal. Já a formação complementar, visto aqui por meio dos programas de empreendedorismo, repercutiu positivamente no propósito ao qual está objetivado.

De fato, pesquisa prévia (MARTINS; PEREIRA; LIMA-FILHO, 2003) mostra que o estímulo e a iniciação da família são fundamentais para a construção do espírito empreendedor e da autoconfiança em jovens universitários.

Verificou-se o impacto positivo da formação religiosa nos jovens empreendedores entrevistados, os quais afirmaram que sua formação de valores e da sua personalidade teve contribuição dos conceitos cristãos. A crença, a autoconfiança e a preocupação com o ser humano, tanto na geração de emprego quanto na formação de laços de amizade e respeito a todas as pessoas próximas, caracterizaram-se como reflexo da convivência em ambientes familiares e religiosos. Eles acreditam que, se fossem cumprir rigorosamente o que a doutrina católica lhes dita, possivelmente não estivessem no caminho do empreendedorismo. Isso porque, em seus relatos, os valores do catolicismo caminham para outro lado, o lado mais social e humano, mais preocupado com o próximo e com as questões de voluntariado e de bem-estar para todos. Acham, no íntimo, que estão fazendo algo de errado. Aliás, esse comportamento é explicado por Max Weber, em sua obra A ética protestante e o espírito do capitalismo (WEBER, 1987), escrita no princípio do século passado.

Observou-se, ainda, o pouco apelo de interesse por questões de formação política. A militância política está colocada como de baixa prioridade no contexto de sua formação; muito claramente porque a política está representada por sujeitos que não se perfilam de seu modelo de influência. Pelo contrário, a resistência atual aos conceitos da política se faz presente, assim também refletindo os aspectos de formação de valor baseados no seu ambiente de convívio. Há que se considerar, portanto, que, assim como a família contribui para o desenvolvimento de valores empreendedores, pode, também, ter influenciado negativamente pela não insistência aos aspectos relativos à valorização da política para desenvolvimento de uma sociedade democrática.

As entrevistas realizadas apontam que o sucesso vem com dedicação ao trabalho, desafios e incertezas, que necessariamente precisam ser enfrentados com o apoio da família e dos valores recebidos para sua conduta social. 
As considerações apontadas anteriormente levam a interpretar que o relacionamento entre esse grupo de jovens e o empreendedorismo, primeiramente, é algo novo para a maioria, refletindo um glamour em que a esperança e o otimismo são característicos. Assim, pode se concluir que foi um relacionamento mais motivado por interesses familiares, ou mesmo, por uma pressão social sobre esses jovens, do que pela vontade individual. Embora, nos discursos, a presença da motivação para empreender esteja centrada na autorrealização, deve-se considerar a real interpretação quanto às verdadeiras intenções da família.

Até quando pode durar o relacionamento entre jovem e empreendedorismo? Pode-se desenvolver uma estratégia pedagógica que estimule o empreendedorismo nos jovens? São questões às quais se espera que sejam respondidas em novos estudos nessa temática.

No entanto, podem-se apresentar algumas evidências extraídas de outros estudos, como os conduzidos por Cooper, Bottomley e Gordon (2004) e Lucas e Cooper (2004). Esses trabalhos revelam que vários tipos de programas de educação para estudantes universitários, que focalizem o desenvolvimento do conhecimento $e$ a habilidade para a criatividade, inovação e propensão ao risco, têm um grande potencial de alavancar o desenvolvimento econômico de diferentes maneiras.

Fayolle (2000) ressalta que é fundamental, nas escolas superiores, a criação de um ambiente empreendedor. Para ele, os cursos de graduação deveriam prever atividades de empreendedorismo desde o início em sua estrutura curricular, de modo a encorajar o espírito empreendedor entre a população universitária. Robertson et al. (2003) também partilham do pensamento de que a educação empreendedora, de fato, apresenta um papel crucial na formação do empreendedor.

Os resultados do presente estudo revelam que o estado e as universidades devem ter uma clara consciência da necessidade de trabalharem juntos para estimular as novas iniciativas empresariais, como sugerem Robertson et al. (2003) e Henderson e Robertson (1999), já que isso é vital para o crescimento econômico.

O fato de este estudo buscar identificar, num grupo de jovens empreendedores da classe média, algumas explicações para o contexto formador próempreendedorismo, de per si, podem ser consideradas como uma reflexão a ser trabalhada para o contingente populacional de jovens e famílias que desejem uma proximidade com o mundo empreendedor. 
Dario de Oliveira Lima-Filho • Renato Luiz Sproesser • Eber Luis Capistrano Martins

As considerações apontadas levam a acreditar que a convivência familiar gera o indivíduo empreendedor. A proximidade do seio familiar, a iniciação precoce e a aceitação de valores familiares corroboram substancialmente para o processo de formação do jovem empreendedor. Independente de sua aceitação da situação ao seu redor, a sua adaptação é quase que inevitável. Todavia, as influências da educação formal tradicionalmente voltada para o emprego, levam a direção de que a família é o maior provedor de estímulo a cultura empreendedora. Os pais como ídolos são uns dos pilares dessa relação familiar.

A realidade e a necessidade de se ter um referencial, ou seja, uma pessoa a servir de modelo de vida, condicionará o individuo também no caminho empreendedor, sobretudo quando se aborda a questão do empreendedorismo de oportunidade versus o empreendedorismo de necessidade.

Os caminhos do contexto neoliberal apontam que o desafio da sociedade atual é orientado pelo entendimento das novas relações com o trabalho, em que pese as mudanças ocorridas na oferta de empregos. Empregadorismo ou Empreendedorismo não devem ser tratados como instrumentos de correção social, mas sim como instrumentos de identificação das necessidades individuais de realização do trabalho com prazer, gerando inovação e riqueza para a sociedade.

Compete à família o papel de mostrar, a seus jovens, valores que destaquem suas potencialidades e capacidades inovadoras. Não basta o incentivo pró-empreendedorismo, não basta ensinar empreendedorismo, se faz necessário entender que a aceitação pelo jovem será tão benéfica quanto maior for o estimulo ao prazer e à inovação via trabalho. Touraine (1999) acredita que, em matéria de política social, é preciso primeiro dar primazia aos problemas do trabalho; é preciso elaborar uma política de trabalho que seja compatível com as novas condições da vida econômica, com a rapidez das mudanças tecnológicas e abertura das economias nacionais.

Debater as questões que cercam o empreendedorismo leva a considerar que o estágio inicial desta temática está presente, promovendo constantes reflexões sobre o quadro de aplicação na esfera social. 


\title{
Entrepreneurship and young entrepreneur
}

\begin{abstract}
This study aim to analyze the characteristics of a group of young entrepreneurs, as well as its opinions how much is the importance of the family, the formal education and the complementary formation in its trajectory for the entrepreneurship. For in such a way, a research was lead, by means of deep interviews with a sample of 16 young entrepreneurs of the middle class, egresses of entrepreneurship courses. The results point that in the trajectory for the entrepreneurship the inheritance of the familiar culture, motivating interests of reproduction and social ascension, was decisive so that these young ones if directed for the world of the businesses. In the perception of the interviewed ones, the success came with devotion to the work and the challenges and uncertainties had been faced with the support of the family and the received values. The speech of the young entrepreneur is optimist and it places it as individual whose history of life values independence in the way to act and the necessity to guarantee its future, leading its proper way.
\end{abstract}

Key-words: New businesses. Enterprising formation.Enterprising education.

\section{Entrepreneurship and Young Entrepreneur}

\begin{abstract}
The objective of this paper was to analyze young entrepreneur's characteristics and views about family importance, formal education and training courses on the trajectory to entrepreneurship. A survey using in-depth interviews was conducted with 16 young entrepreneurs from the middle class, graduates in entrepreneurship. The results show that family cultural inheritance, which motivates social mobility and reproduction concerns, was crucial to their entrance in the business world. The young entrepreneur's success came with dedication to work and challenges and uncertainties have been faced with support received from family values. The young entrepreneurs are optimistic, have a live history which valorize independency and need to ensure their future, leading their own way.
\end{abstract}

Key-words: New business. Entrepreneurial training. Entrepreneurship education. 
Dario de Oliveira Lima-Filho • Renato Luiz Sproesser • Eber Luis Capistrano Martins

\section{REFERÊNCIAS}

ALBERTI, V. História oral: a experiência do CPDOC. Rio de Janeiro: Centro de Pesquisa e Documentação História Contemporânea do Brasil, 1989.

BARROS, B. T. B.; PRATES, M. A. S. O estilo brasileiro de administrar. São Paulo: Atlas, 1996.

BOURDIEU, P. As contradições da herança. In: BOURDIEU, P. A miséria do mundo. 5. ed. Rio de Janeiro: Vozes, 2003.

CIELO, I. D. Perfil do pequeno empreendedor: uma investigação das características empreendedoras nas empresas de pequena dimensão. Dissertação (Mestrado em Engenharia de Produção) - Universidade Federal de Santa Catarina. Florianópolis, 2001.

COOPER, S. Y.; BOTTOMLEY, C.; GORDON, J. Stepping out of the classroom and up the ladder of learning: an experiential learning approach to entrepreneurship education. Industry and Higher Education, London, UK, v. 18, n. 1, p.11-22, Feb. 2004.

DaMATTA, R. O que faz o Brasil, Brasil? Rio de Janeiro: Rocco, 1984.

De MASI, Domenico. Ócio criativo. 2. ed. Rio de Janeiro: Sextante, 2000.

DOLABELA, F. Oficina do empreendedor. São Paulo: Cultura, 1999.

DOLABElA, F. A vez do sonho. São Paulo: Cultura, 2000.

DOLABELA, F. Empreendedorismo: reinvenção através do sonho. Revista Sebrae, Brasília, p. 63, out./nov. 2001.

DORNELAS, J. C. Empreendedorismo: transformando idéias em negócios. Rio de Janeiro: Campus, 2001.

DRUCKER, P. F. Inovação e espírito empreendedor. São Paulo: Pioneira, 1986.

FARREL, L. C. Entrepreurship: fundamentos das organizações empreendedoras. São Paulo: Saraiva, 1993. 
FAYOLLE, A. Dês réflexuions et dês axés stratégiques pour développer

l'enseignement de l'entrepreneuriat. Gestion, Montreal, Canadian v. 17, n. 2, p. 133-154, 2000.

FERRARI, A. T. Fundamentos de sociologia. São Paulo: McGrawHill, 1982.

FILION, L. J. Empreendedorismo: empreendedores e proprietários-gerentes de pequenos negócios. Revista de Administração, São Paulo, v. 34, n. 2, p. 528, 1999.

FILION, L. J. O empreendedorismo como tema de estudos superiores. In: DOLABELA, F. et al. Empreendedorismo, ciência, técnica e arte. Brasília: Instituto Euvaldo Lodi (CNI Nacional), 2000.

GEM - Global Entrepreneurship Monitor. Empreendedorismo no Brasil. Curitiba: 2002

GOHN, M. G. Movimentos sociais e educação. São Paulo: Cortez, 2001.

GRIFFIN, A.; HAUSER, J. R. The voice of the consumer. Marketing Science, Hanover, Maryland, USA, v. 12, p. 1-25, Winter 1993.

GRUN, R. Dinheiro no bolso, carrão e loja no shopping: estratégias educacionais e estratégias de reprodução social em famílias de imigrantes armênios. In: NOGUEIRA, M. A.; ALMEIDA, A. M. F. A escolarização das elites. Rio de Janeiro: Vozes, 2002.

HANDY, C. The hungry spirit. Londres: Hutchinson/Random House, 2001.

HENDERSON, R.; ROBERTSON, M. Who wants to be an entrepreneur? Young adult attitudes to entrepreneurship as a career. Education + Training,

Bingley, UK, v. 41, n. 5, p. 236-245, 1999.

KLAPPER, R. Government goals and entrepreneurship education: an investigation at a Grande Ecole in France. Education + Training, Bingley, UK v. 46, n. 3, p. 127-137, 2004.

LEZANA, A. G. R.; TONELLI, A. O comportamento do empreendedor. In: MORI, F. Empreender: identificando, avaliando e planejando um novo negócio. Florianópolis: Escola de Novos Empreendedores, 1998. 
Dario de Oliveira Lima-Filho • Renato Luiz Sproesser • Eber Luis Capistrano Martins

LIMA-FILHO, D. O.; SPROESSER, R. S. Setor agronegócio: a mola mestra da balança comercial. In: BARRIZZELLI, N.; SANTOS, R. C. Lucratividade pela inovação: como eliminar ineficiências nos seus negócios e na cadeia de valor. Rio de Janeiro: Campus Elsevier, 2006.

LODI, J. B. Sucessão e conflito na empresa familiar. São Paulo: Pioneira, 1987.

LONGEN, M. T. Um modelo comportamental para o estudo do perfil do empreendedor. Dissertação (Mestrado em Engenharia da Produção) Universidade Federal de Santa Catarina. Florianópolis, 1997.

LUCAS, W. A.; COOPER, S. Y. Enhancing self-efficacy to enable entrepreneurship: The case of CMI's Connections. MIT Sloan Working Paper 4489-04. Cambridge: MIT Sloan School of management, 2004.

MARTINS, E. L. C.; PEREIRA, S. C. F.; LIMA-FILHO, D. O. Business administration undergraduate students and their entrepreneurship dream: an exploratory study. In: BALAS Annual Conference, 2003, FGV-São Paulo. Proceedings... São Paulo: Business Association of Latin American StudiesBALAS, 2003.

MINAYO, M. C. S.; DESLANDES, S. F. Pesquisa social: teoria, método e criatividade. 22. ed. Rio de Janeiro: Vozes, 2002.

MORIN, E. M. Os sentidos do trabalho. Revista de Administração de Empresas, São Paulo, v. 41, n. 3, p. 8-39, 2001.

MOTTA, F. C. P.; CALDAS, M. P. (Orgs.). Cultura organizacional e cultura brasileira. São Paulo: Atlas, 1997.

NOGUEIRA, M. A.; ALMEIDA, A. M. F. A escolarização das elites. Rio de Janeiro: Vozes, 2002.

OLIVEIRA, M. A. Valeu! Passos na trajetória de um empreendedor. São Paulo: Nobel, 1995.

PATI, V. O empreendedor: descoberta e desenvolvimento do potencial empresarial. In: PEREIRA, Heitor. Criando seu próprio negócio. Brasília: Ed. Sebrae, 1995. 
POCHMANN, M. O trabalho sob fogo cruzado: exclusão, desemprego e precarização no final do século. 3. ed. São Paulo: Contexto, 2002.

QUEIRÓZ, M. I. P. Relatos orais do indizível ao dizível. Ciência e Cultura, Campinas, v. 39, n. 3, p. 272-286, 1987.

ROBERTSON, M. et al. Barriers to start-up and their effect on aspirant entrepreneurs. Education + Training, Bingley, UK, v. 45, n. 6, p. 308-316, 2003.

SENNETT, R. A corrosão do caráter. Rio de Janeiro: Record, 2000.

SHEEDY, E. Guia do empreendedor para fazer a empresa crescer. São Paulo: Nobel, 1996.

TELES, M. L. S. Psicodinâmica do desenvolvimento humano. 9. ed. Rio de Janeiro: Vozes, 2001

TOURAINE, A. Como sair do Liberalismo? Bauru: EDUSC, 1999.

WEBER, M. A ética protestante e o espírito do capitalismo. 5. ed. São Paulo: Pioneira, 1987. 